\title{
Dexmedetomidine as a non-triggering anesthetic agent in a patient with MELAS syndrome and systemic sepsis \\ - A case report -
}

Received December 21, 2018

Revised 1st, January 29, 2019 2nd, March 8, 2019

Accepted March 14, 2019

\section{Corresponding author}

Ki Tae Jung, M.D., Ph.D.

Department of Anesthesiology and

Pain Medicine, Chosun University

Hospital, 365 Pilmun-daero, Dong-

gu, Gwangju 61453, Korea

Tel: 82-62-220-3223

Fax: 82-62-223-2333

E-mail: mdmole@chosun.ac.kr

\section{ORCID}

https://orcid.org/0000-0002-2486-9961

\section{Sang Hun Kim, Su Yeong Park, and Ki Tae Jung}

Department of Anesthesiology and Pain Medicine, Chosun University Hospital, Gwangju, Korea

Background: The selection of anesthetic agents is important in mitochondrial myopathy, encephalopathy, lactic acidosis, and stroke-like episodes (MELAS) syndrome patient because serious and unexpected complications can occur after anesthetic exposure.

Case: A 30-year-old man with MELAS syndrome and sepsis underwent colectomy. Propofol was administered by step-wise until target effect-site concentration (Ce) $1.0 \mu \mathrm{g} / \mathrm{ml}$ and stopped for the loss of consciousness and to avoid hemodynamic instability. After the loss of consciousness, total intravenous anesthesia (TIVA) using dexmedetomidine $(1.0 \mu \mathrm{g} / \mathrm{ml} / \mathrm{h})$ and remifentanil (1-4 $\mathrm{ng} / \mathrm{ml}$ of $\mathrm{Ce}$ ) was performed for the maintenance of anesthesia to avoid malignant hyperthermia and mitochondrial dysfunction. During the surgery, the bispectral index score stayed between 26 and 44, and increased to 97 after the end of anesthesia.

Conclusions: TIVA with dexmedetomidine and remifentanil as non-triggering anesthetic agents in patients with MELAS syndrome and systemic sepsis may have advantages to decrease damages associated with mitochondrial stress and metabolic burden.

Keywords: Dexmedetomidine; Intravenous anesthesia; MELAS syndrome; Remifentanil; Sepsis.
Anesthesiologists often encounter patients with mitochondrial disease in the operating room. Since mitochondria are the essential source of metabolism in the intracellular organs of mammals, mitochondrial dysfunction is associated with clinical manifestations in major organs, such as the brain, lungs, liver, and kidneys, which require abundant energy [1,2] Thus, mitochondrial disease is very stressful for the anesthesiologist because mitochondrial dysfunction causes various organ dysfunctions, including cardiac depression, respiratory failure, and myopathy.

MELAS (mitochondrial myopathy, encephalopathy, lactic acidosis, and stroke-like episodes) syndrome is one of the mitochondrial diseases caused by a mitochondrial DNA mutation. Avoiding metabolic burden is extremely important for patients with MELAS syndrome because it can result in malignant hyperthermia, hypothermia, and resistance to muscle relaxants during surgery $[1,2]$. The selection of anesthetic agents is very important because serious and unexpected complications can occur after anesthetic exposure, although many different anesthetic techniques have been used successfully for MELAS patients [2]. Total intravenous anesthesia (TIVA) with propofol can be used as an alternative to inhaled anesthetics to avoid the risk of complications, such as malignant hyperthermia and rhabdomyolysis [1]. However, pro-

This is an Open Access article distributed under the terms of the Creative Commons Attribution Non-Commercial License (http://creativecommons.org/licenses/by-nc/4.0) which permits unrestricted non-commercial use, distribution, and reproduction in any medium, provided the original work is properly cited. 
pofol is associated with a risk of propofol infusion syndrome (PRIS), especially in patients with metabolic acidosis [2].

Here we report the use of dexmedetomidine and remifentanil for TIVA instead of propofol in a MELAS syndrome patient with systemic sepsis who was at an increased risk for metabolic burden.

\section{CASE REPORT}

A 30-year-old man $(172 \mathrm{~cm} / 75 \mathrm{~kg})$ was admitted to the emergency room (ER) due to mechanical ileus with an enterocutaneous fistula. He was admitted to the emergency room because of abdominal pain, difficulty in defecation, and sudden changes in mental status, which included stupor after vomiting. He suffered from sepsis and his vital signs showed $60 / 40 \mathrm{mmHg}$ blood pressure (BP) and 140 beats/min heart rate (HR).

He had been diagnosed with MELAS syndrome seven years ago. He had a partial seizure and was medicated with carbamazepine (1,200 mg/day) and valproic acid (1,000 mg/ day). He also had mental retardation and a history of cerebral infarction in the region of the left middle cerebral artery and right posterior inferior cerebellar artery about seven years ago. He also had a history of occasional lactic acidosis (> 100 $\mathrm{mg} / \mathrm{dl})$.

Abnormal laboratory findings included: white blood cells, $2.9 \times 10^{3} / \mu \mathrm{l}$; lactic acid, $142.1 \mathrm{mg} / \mathrm{dl}$; aspartate transaminase, 141.1 U/L; alanine transaminase, $124.7 \mathrm{U} / \mathrm{L}$; creatine kinase (CK), $353.0 \mathrm{U} / \mathrm{L}$; CK-MB, $20.79 \mathrm{ng} / \mathrm{ml}$. blood urine nitrogen, $36.7 \mathrm{mg} / \mathrm{dl}$; creatinine, $1.10 \mathrm{mg} / \mathrm{dl}$; prothrombin time, 17.7 $\mathrm{s}$; international normalized ratio, 1.57; and activated partial thromboplastin time, $56.7 \mathrm{~s}$. The initial results of arterial blood gas analysis (ABGA) at the ER revealed metabolic acidosis ( $\mathrm{pH}$ 7.170, $\mathrm{PaO}_{2} 129.5 \mathrm{mmHg}, \mathrm{PaCO}_{2} 36.8 \mathrm{mmHg}$, base excess $-15.2 \mathrm{mM} / \mathrm{L}$, and $\mathrm{HCO}_{3}{ }^{-} 13.6 \mathrm{mM} / \mathrm{L}$ ) and lactic acidosis (lactate $131.7 \mathrm{mg} / \mathrm{dl}$ ). His electrocardiogram showed an ST-elevation on the anterior lead which was diagnosed as Wolff-Parkinson-White syndrome. His cardiac enzyme results were as follows: high sensitivity troponin-T, $205 \mathrm{ng} / \mathrm{L}$; and pro B-type natriuretic peptide, $313.7 \mathrm{pg} / \mathrm{ml}$. He also suffered from hypoglycemia (55.1 mg/dl).

Dobutamine was administered at a rate of $10 \mu \mathrm{g} / \mathrm{kg} / \mathrm{min}$ and norepinephrine was administered at a rate of $0.5 \mu \mathrm{g} / \mathrm{kg}$ / min before surgery. He showed a drowsy-to-stupor mental status and his parents agreed not to perform cardiopulmonary resuscitation in the event of a cardiac arrest. An emergency total colectomy and terminal ileostomy were planned.

A careful anesthesia plan was prepared considering the risks of anesthetic agents in his condition, particularly because of the sepsis. We avoided inhalation anesthetics because of their potential to cause mitochondrial myopathy or malignant hyperthermia. Administering TIVA with propofol and remifentanil was considered but there were risks of pronounced adverse hemodynamic effects and PRIS because the patient suffered from severe septic shock and metabolic acidosis. Thus, we planned to carefully use propofol only during the induction of anesthesia and to replace propofol with dexmedetomidine to maintain sedation during the surgery after the patient lost consciousness.

The patient was transferred to the operating room and standard monitoring devices (Carescape ${ }^{\circledR}$ B850, GE Healthcare, USA) for electrocardiogram, noninvasive BP, pulse oximetry $\left(\mathrm{SpO}_{2}\right)$, and capnography were attached. The baseline results of the standard monitor were $\mathrm{SpO}_{2} 99 \%$, noninvasive BP 114/46 mmHg, HR 141 beats/min, and temperature $39.1^{\circ} \mathrm{C}$. A bispectral index (BIS monitor A-2000, Aspect Medical Systems, USA), neuromuscular monitor (888418 M-NMT MechanoSensor, Datex-Ohmeda Inc., Finland), and FloTrac/ EV1000 (Edwards Lifesciences, USA) were prepared for the careful monitoring and early detection of adverse events. Radial arterial cannulation was done before anesthesia induction.

After preoxygenation with $100 \% \mathrm{O}_{2}$, anesthesia was induced with propofol (Fresofol ${ }^{\circledR}$, Fresenius Kabi, Austria) using target-controlled infusion devices (Orchestra, Fresenius Kabi, France). The target effect-site concentration (Ce) of propofol was increased step-wise $(0.2 \mu \mathrm{g} / \mathrm{ml}$ per $1 \mathrm{~min})$ to avoid hemodynamic instability, while the patient's vital signs were monitored (Fig. 1). During the infusion of propofol, dexmedetomidine infusion $(1.0 \mu \mathrm{g} / \mathrm{kg} / \mathrm{h})$ without a loading dose was started simultaneously. After five minutes, the patient lost consciousness and his BIS score became 44 when the Ce of propofol reached $1.0 \mu \mathrm{g} / \mathrm{ml}$. Then, the Ce of propofol was adjusted to $0 \mu \mathrm{g} / \mathrm{ml}$ and only dexmedetomidine was used for the sedation. After that, the infusion of remifentanil (Ultiva ${ }^{\mathrm{TM}}$, GlaxoSmithKline, UK) was started (target Ce, 1 ng/dl). After the administration of rocuronium $(0.6 \mathrm{mg} / \mathrm{kg})$, endotracheal intubation was performed when the train-of-four (TOF) 
Propofol (Ce) $\quad 1.0 \mu \mathrm{g} / \mathrm{ml}-/ /$ stopped

Escalating $0.2 \mu \mathrm{g} / \mathrm{ml} / \mathrm{min}: 1.0 \mu \mathrm{g} / \mathrm{ml}$ after $5 \mathrm{~min}$ : loss of consciousness, BIS 44

Dexmedetomidine $1.0 \mu \mathrm{g} / \mathrm{kg} / \mathrm{h}$ continuous infusion $1 /$ stopped about 30 min before end of surgery

Remifentanil $(\mathrm{Ce}) \quad 1.0 \mathrm{ng} / \mathrm{ml} \longrightarrow 2.0 \mathrm{ng} / \mathrm{ml} \longrightarrow 4.0 \mathrm{ng} / \mathrm{ml} \longrightarrow / /$ stopped about $5 \mathrm{~min}$ before end of surgery

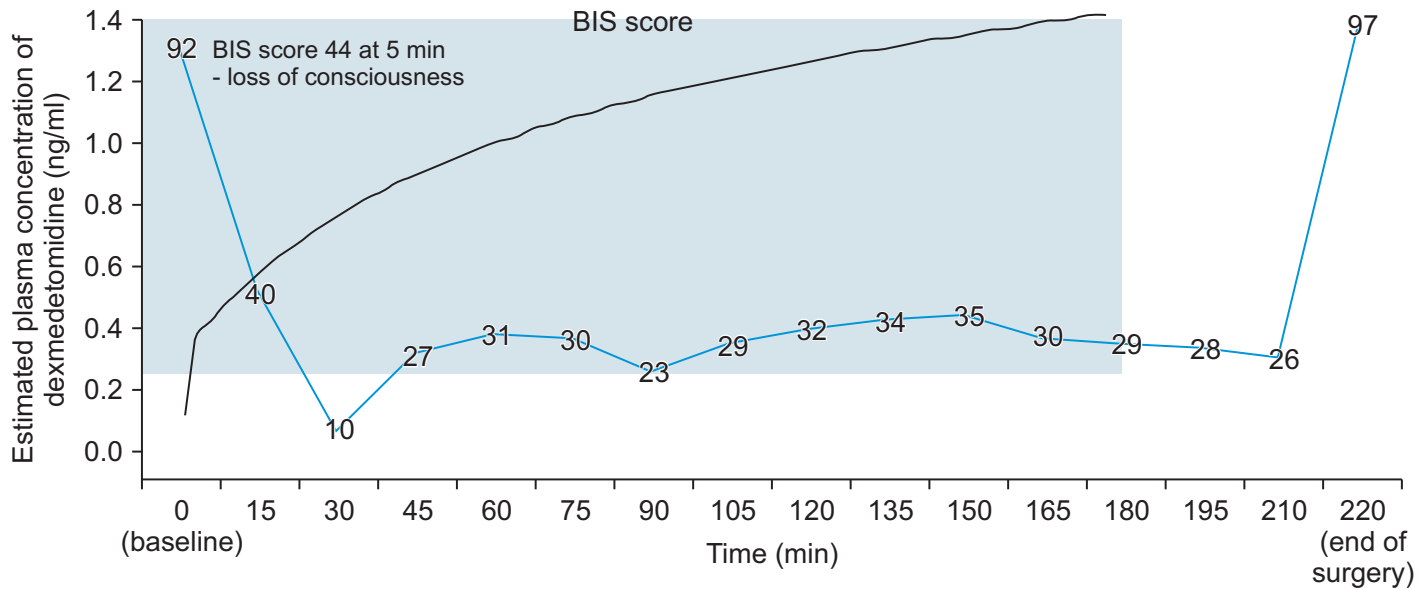

Fig. 1. Timeline of anesthesia during the surgery. Propofol was administered by target-controlled infusion by step-wise escalation of the effect-site concentration $(0.2 \mu \mathrm{g} / \mathrm{ml}$ per $1 \mathrm{~min})$. After five minutes, the patient lost consciousness and his BIS score became 44 when the Ce of propofol was 1.0 $\mu \mathrm{g} / \mathrm{ml}$. During the infusion of propofol, dexmedetomidine infusion $(1.0 \mu \mathrm{g} / \mathrm{kg} / \mathrm{h})$ without a loading dose was started simultaneously. After the loss of consciousness, the $\mathrm{Ce}$ of the propofol was adjusted to $0 \mu \mathrm{g} / \mathrm{ml}$ and anesthesia was maintained with dexmedetomidine $(1.0 \mu \mathrm{g} / \mathrm{ml} / \mathrm{h})$ and remifentanil (1-4 ng/ml of Ce). The blue line shows the change in the BIS score. The black line shows the change in the estimated plasma concentration of dexmedetomidine. The blue box shows the effective dexmedetomidine concentration in clinically ill patients $(0.22-2.50 \mathrm{ng} / \mathrm{ml})[4]$. Ce: effect site concentration, BIS: bispectral index.

reached 0 . Mechanical ventilation with $60 \% \mathrm{O}_{2}$ was started with a tidal volume of $600 \mathrm{ml}$ and a respiratory rate of 12 breaths per minute, which was adjusted to keep the end-tidal $\mathrm{CO}_{2}$ below $40 \mathrm{mmHg}$ and the peak inspiratory pressure below $30 \mathrm{mmHg}$ (Fig. 2). The patient's esophageal temperature was monitored and his body was cooled with an ice bag because of his fever due to sepsis (Fig. 2). Fluid management was performed according to the stroke volume variation (SVV) with plasma solution (Fig. 3). The target Ce of remifentanil was adjusted (1-4 ng/ml) according to the patient's hemodynamic status (Fig. 1). The BIS score stayed within 26 and 44 during the surgery. The infusion of dobutamine and norepinephrine was continued throughout the surgery. The mean arterial pressure of the patient was maintained above $50 \mathrm{mmHg}$ and the cardiac output was maintained within 6 to $10 \mathrm{~L} / \mathrm{min}$ during the surgery. SVV decreased from $16 \%$ to $12 \%$ at the end of surgery, but tachycardia still remained.

About 80 min after starting the surgery, the patient suddenly became hypotensive (BP, 47/18 mmHg; HR, 42 beats/ min), and $1 \mathrm{mg}$ epinephrine and $5 \mathrm{U}$ vasopressin were administered. His vital signs stabilized again and there was no other event during the surgery (Fig. 3).

Dexmedetomidine infusion was stopped about $30 \mathrm{~min}$ be- fore the end of surgery and the target Ce of remifentanil was adjusted to 0 about five minutes before the end of surgery (Fig. 1). The BIS score increased to 97 after the end of anesthesia, which was about $40 \mathrm{~min}$ after the infusion was stopped, and he opened his eyes upon verbal command about three minutes later. Then, $200 \mathrm{mg}$ sugammadex was administered (the TOF ratio was $13 \%$ at that time) and extubation was performed about two minutes later when the TOF ratio reached $100 \%$ and adequate tidal volume during spontaneous breathing was restored.

The total administrated doses of propofol, dexmedetomidine, and remifentanil were approximately $50 \mathrm{mg}, 225 \mu \mathrm{g}$, and $2.15 \mathrm{mg}$, respectively. The estimated concentration of dexmedetomidine was calculated with an ASAN Pump (version 1.6, Bionet Co. Ltd., Korea) using the pharmacokinetics data of intravenous dexmedetomidine in Korean subjects [3]. The calculated plasma concentration of dexmedetomidine reached an effective plasma concentration in clinically ill patients $(0.22-2.50 \mathrm{ng} / \mathrm{ml})$ within three minutes [4].

During the surgery, a glucose supplement of $50 \%$ dextrose in water ( $250 \mathrm{~g}$ of glucose in $500 \mathrm{ml}$ of water) was given. Glucose was administered at a rate of $8 \mathrm{~g} / \mathrm{h}$ for about three hours and the patient's blood glucose level was $101 \mathrm{mg} / \mathrm{dl}$ 


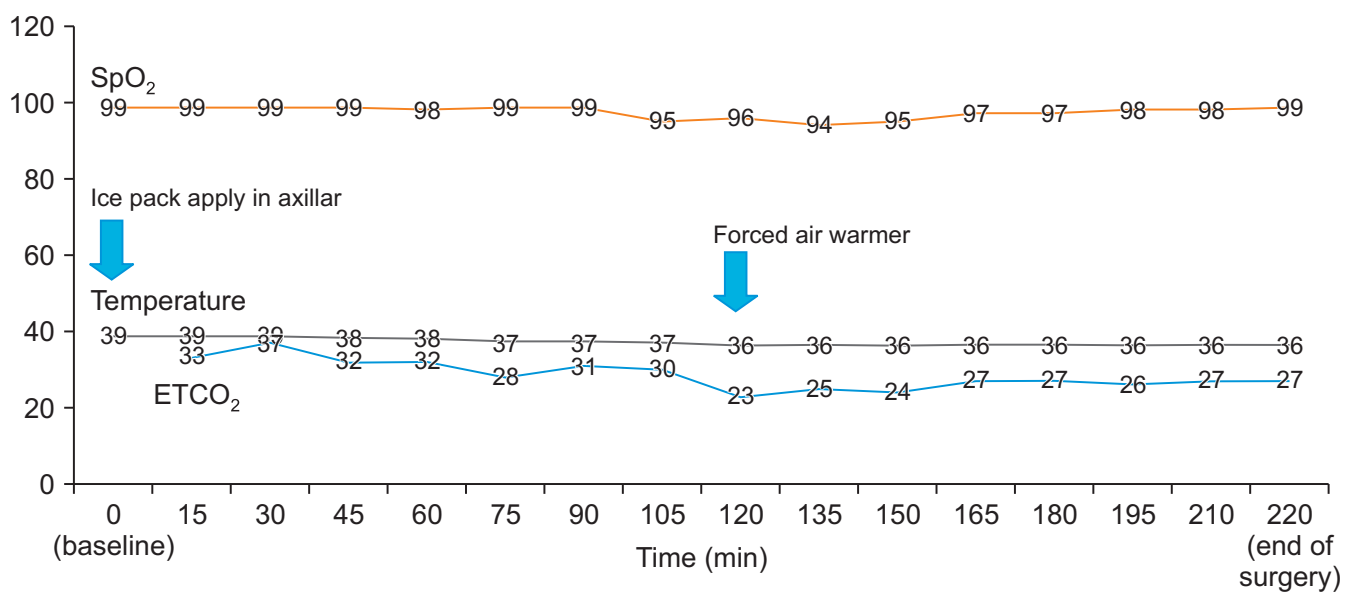

\begin{tabular}{lrrrr}
\hline $\mathrm{pH}$ & 7.174 & 7.302 & 7.284 & 7.278 \\
\hline $\mathrm{PaCO}_{2}(\mathrm{mmHg})$ & 36.2 & 24.8 & 25.6 & 33.1 \\
\hline $\mathrm{PaO}_{2}(\mathrm{mmHg})$ & 146 & 184.4 & 260.7 & 256.0 \\
\hline $\mathrm{HCO}_{3}{ }^{-}(\mathrm{mM} / \mathrm{L})$ & 13.4 & 14.6 & 15.3 & 15.6 \\
\hline Base excess & -14.5 & -14.8 & -13.2 & -22.3 \\
\hline Lactate $(\mathrm{mg} / \mathrm{dl})$ & 8.58 & 7.11 & 7.12 & 7.7 \\
\hline Glucose $(\mathrm{mg} / \mathrm{dl})$ & 55.1 & 80 & 77 & 101 \\
\hline
\end{tabular}

Treatment

$50 \%$ dextrose in water:

$8 \mathrm{~g} / \mathrm{h}$

Sodium bicarbonate:

$120 \mathrm{mEq}$ for $30 \mathrm{~min} / /$

Fig. 2. Changes in $\mathrm{SpO}_{2}$, temperature, $\mathrm{ETCO}_{2}$, and the results of $\mathrm{ABGA}$ during the surgery. Metabolic acidosis and hypoglycemia were managed during anesthesia. The patient's temperature was managed carefully to avoid hypothermia or hyperthermia during anesthesia. $\mathrm{SPO}_{2}$ : oxygen saturation, $\mathrm{ETCO}_{2}$ : end-tidal $\mathrm{CO}_{2}$, ABGA: arterial blood gas analysis.

Treatment

Dobutamine:

Norepinephrine:

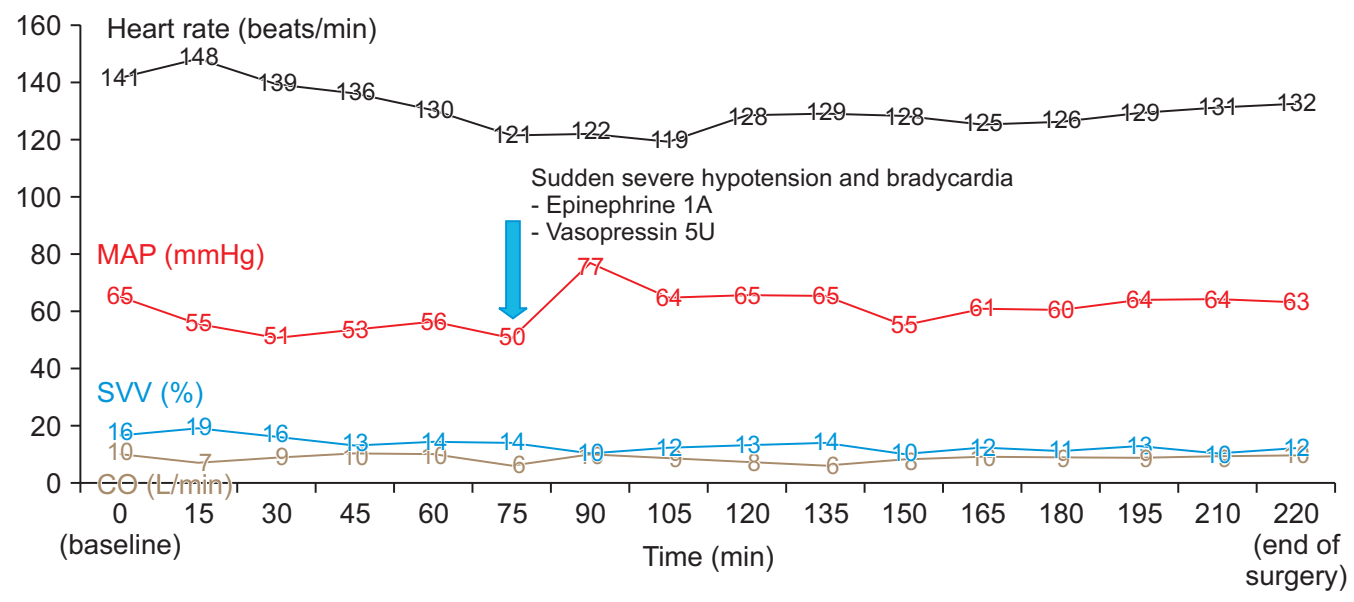

$10 \mu \mathrm{g} / \mathrm{kg} / \mathrm{min}-6 \mu \mathrm{g} / \mathrm{kg} / \mathrm{min}-3 \mu \mathrm{g} / \mathrm{kg} / \mathrm{min}$

$0.5 \mu \mathrm{g} / \mathrm{kg} / \mathrm{min} \longrightarrow 0.75 \mu \mathrm{g} / \mathrm{kg} / \mathrm{min}-1 \mu \mathrm{g} / \mathrm{kg} / \mathrm{min}$

Fig. 3. Hemodynamic data during the surgery. Dobutamine and norepinephrine were administered from the start of anesthesia, and MAP and CO were maintained above $50 \mathrm{mmHg}$ and $6 \mathrm{~L} / \mathrm{min}$, respectively, guided by SW during anesthesia. MAP: mean arterial pressure, SW: stroke volume variation, $\mathrm{CO}$ : cardiac output. 
at the end of surgery. The patient's metabolic acidosis was managed by the administration of sodium bicarbonate and adjustment of his minute ventilation. A total dose of $120 \mathrm{mEq}$ of sodium bicarbonate was administered during the $30 \mathrm{~min}$ utes after induction of anesthesia. His $\mathrm{pH}$ rose above 7.2 and his respiratory rate and tidal volume were adjusted to keep the end-tidal $\mathrm{CO}_{2}$ below $40 \mathrm{mmHg}$. An ice bag was applied at the axilla until his body temperature became $37^{\circ} \mathrm{C}$. A forced air warmer was used to maintain his temperature above $36^{\circ} \mathrm{C}$ throughout the surgery.

The operation lasted about $210 \mathrm{~min}$ and the patient was transferred to the intensive care unit. The final ABGA results in the operating room were as follows: $\mathrm{pH} 7.278, \mathrm{PaO}_{2} 256.0$ mmHg, $\mathrm{PaCO}_{2} 33.1 \mathrm{mmHg}$, base excess $-11.3 \mathrm{mM} / \mathrm{L}, \mathrm{HCO}_{3}{ }^{-}$ $15.6 \mathrm{mM} / \mathrm{L}$, and lactate $64.1 \mathrm{mg} / \mathrm{dl}$. About 3,000 ml of crystalloids was administered during the surgery and the patient's urine output was 1,100 ml. His estimated blood loss was 100 $\mathrm{ml}$.

The patient received critical care for one month but sepsis persisted and his condition worsened daily. Cardiac arrest occurred after a month but cardiopulmonary resuscitation was not performed because his parents previously requested that no resuscitation efforts be made. He died due to septic shock.

\section{DISCUSSION}

In this case report, we conducted a TIVA with dexmedetomidine, instead of Propofol, in a patient with MELAS syndrome to avoid the development of malignant hyperthermia due to inhaled anesthetics or mitochondrial dysfunction due to prolonged propofol infusion.

High-energy requiring tissues, such as the brain, central nervous system, and heart depend on energy delivered by the mitochondria [2]. Mutations in mitochondrial proteins cause mitochondrial dysfunction in major organs, thus, patients with mitochondrial diseases are very susceptible to the stress from surgery and anesthesia. The increased susceptibility to metabolic stress is due to energy failure. And stress can easily result in lactic acidosis when pyruvate is shunted to lactate, instead of oxidative phosphorylation which would generate adenosine triphosphate (ATP) [5]. As a consequence, clinical circumstances which increase the metabolic burden, such as hypoglycemia, hypothermia, acidosis, and hypovolemia, should be avoided in MELAS patients [1,2]. The systemic sepsis of the current patient definitely increased the metabolic burden and challenged anesthesia management. Specifically, unexpected complications may occur from the exposure to anesthetic agents because tissues of the central nervous system which are affected by anesthetics are also profoundly dependent on the mitochondrial function which requires high energy [2].

Although many anesthetic techniques have been introduced as safe methods for patients with mitochondrial disease, perioperative complications may occur by inhibition of metabolism by anesthetic agents. Unfortunately, a general anesthetic agent, such as inhaled anesthetics or propofol, can depress mitochondrial function in patients with mitochondrial defects [2]. They have diminished abilities to generate ATP and use oxygen [2]. The use of halogenated inhalation anesthetics in patients with mitochondrial diseases in association with malignant hyperthermia is controversial [1,2] and the anesthesiologist should beware of the risks [1]. Moreover, patients with mitochondrial diseases are abnormally sensitive to inhaled anesthetics. One to two times the $\mathrm{EC}_{50}$ of inhalation anesthetics inhibits complex I of the mitochondrial respiratory chain/oxidative phosphorylation system [2]. Specifically, patients with MELAS syndrome have mutations in the mitochondrial genome associated with subunits of complexes I [5]. The sensitivity to inhaled anesthetics is markedly increased when the function of complex I is abnormal [2]. Propofol also has the same risk as inhaled anesthetics. A limited dose of propofol as a bolus during induction has little risk but prolonged infusion presents a risk for the development of PRIS, characterized by lactic acidosis, lipidemia, rhabdomyolysis, and cardiovascular collapse [2]. Propofol can also decrease mitochondrial function by different mechanisms, such as the inhibition of fatty acid transport into the mitochondrion, complexes I/II/IV inhibition, and oxidative phosphorylation $[2,6]$. Propofol may also inhibit acylcarnitine transfer into the mitochondria, which leads to an increase in serum acylcarnitines and profound metabolic acidosis [7]. Thus, some patients with MELAS syndrome are susceptible to adverse effects, such as PRIS, after the use of propofol [2], although there has been one report where propofol infusion was used safely in a MELAS syndrome patient [1]. Patients with mitochondrial dysfunction may be at increased risk for PRIS and high-dose and prolonged infusion of propofol are 
risk factors for PRIS [2]. Thus, caution is advised in the selection of propofol as a primary anesthetic agent in MELAS patients. Moreover, propofol also increases morbidity and mortality in patients with sepsis [8].

We chose dexmedetomidine for maintenance of sedation during anesthesia to avoid the possible adverse effects of inhaled anesthetics and propofol. However, dexmedetomidine may have advantages for both MELAS syndrome and systemic sepsis. First, there has been no report on the adverse effects of dexmedetomidine in mitochondrial disease patients. Successful trials have been conducted using nontriggering anesthesia with dexmedetomidine in patients with mitochondrial disease [9]. The effect of dexmedetomidine on the central nervous system is different from that of general parenteral anesthetics (propofol, etomidate, ketamine, or benzodiazepine) [10]. The majority of their effects occur via ligand-gated ion channels, $\gamma$-aminobutyric acid or $\mathrm{N}$-methylD-aspartate but dexmedetomidine acts on $\alpha 2$ adrenoceptors in the locus coeruleus. Dexmedetomidine may avoid the aforementioned mechanism which triggers adverse effects in patients with mitochondrial disease. It also has the benefit of less respiratory depression, which may be an advantage during the emergence from anesthesia. A recent study showed that dexmedetomidine decreased damages associated with mitochondrial stress [11]. It relieved neuronal damage caused by mitochondrial membrane oxidative stress and reduced damage to the mitochondrial-related enzyme system activity. Second, the use of dexmedetomidine may also be advantageous in patients with sepsis. Dexmedetomidine has anti-inflammatory properties. It promoted macrophage phagocytosis and reduced inflammatory cytokines in patients with sepsis [12]. Theoretically, it may also have a myocardial protective effect by attenuating sympathetic hyperdynamic responses [13].

In the current patient, we used a limited dose of propofol for the induction of anesthesia, instead of dexmedetomidine loading, because it takes a relatively long time to produce a loss of consciousness on an anesthetic level and can produce hypotension or bradycardia [13]. This choice would also help avoid the risk of PRIS [2]. After, we started the continuous infusion of dexmedetomidine. During the surgery, the BIS score of the patient remained less than 35 and became 97 upon waking. However, further research should be done to determine the actual plasma concentration of dexmedetomi- dine needed for anesthesia, and to validate the safety of dexmedetomidine in patients with MELAS syndrome. We also made efforts to reduce the metabolic burden of the patient. Mechanical ventilation was adjusted to maintain optimal oxygenation. Careful management, such as sodium bicarbonate administration and minute ventilation adjustment according to the patient's acid-base status, was conducted to reduce acidosis. Glucose was administered to correct his hypoglycemia. Continuous temperature monitoring and management were done and the patient became normothermia at the end of surgery. Volume management was conducted with the guidance of SVV and cardiac output to avoid hypovolemia and his mean arterial pressure was maintained above 50 during the surgery, despite systemic sepsis. The patient was transferred to the intensive care unit with stable vital signs after anesthesia. However, he could not endure the sustained sepsis and died after a month.

However, there are several limitations to the clinical application of the anesthetic technique in this case report. First, dexmedetomidine alone does not guarantee adequate anesthetic depth during general anesthesia. It is a still a sedativeanalgesic agent [13] and there are few reports about the use of dexmedetomidine as the sole anesthetic agent. Thus, the conventional dose of dexmedetomidine for sedation may lead to perioperative recall or awareness. And there is a possibility that the high dose of dexmedetomidine required to achieve the anesthetic depth needed for the surgery may cause hemodynamic instability. However, a recent report showed that dexmedetomidine could be used as an anesthetic agent during laparotomic surgery and maintained anesthesia comparable to propofol [14]. When dexmedetomidine was administered by infusion $(0.5 \mu \mathrm{g} / \mathrm{kg} / \mathrm{h})$ after a $1 \mu \mathrm{g} / \mathrm{kg}$ bolus injection, the intraoperative BIS values were maintained lower than in propofol infusion ( $1 \mathrm{mg} / \mathrm{kg}$ bolus followed by $50 \mu \mathrm{g} / \mathrm{kg} / \mathrm{min}$ infusion) during laparotomy surgery. According to the protocol of the study and applying the weight of the patient in our case, the dose of dexmedetomidine needed for three hours of general anesthesia would be $187.5 \mu \mathrm{g}$, which is less than the dose of dexmedetomidine used in our case $(225 \mu \mathrm{g})$. Second, the estimated plasma concentration of dexmedetomidine in the current case does not represent the real plasma concentration. The patient in our case was critically ill with systemic sepsis, however, the estimated plasma concentration was calculated by pharmacokinetic data from healthy volunteers. 
Therefore, it is difficult to apply the plasma concentration presented in this case to clinical practice. Further research and clinical trials are needed to investigate the administration of dexmedetomidine as a sole anesthetic.

Despite these limitations, the use of dexmedetomidine as the main anesthetic agent may have the advantage of a nontriggering anesthetic agent in patients with a mitochondrial disease, such as MELAS syndrome. Dexmedetomidine may be especially advantageous by decreasing the damage associated with mitochondrial stress in cases of increased metabolic burden, such as systemic sepsis. In conclusion, TIVA with dexmedetomidine and remifentanil for a patient with MELAS syndrome and systemic sepsis may be considered as a new safe way to avoid the adverse effect of anesthetic agents.

\section{CONFLICTS OF INTEREST}

No potential conflict of interest relevant to this article was reported.

\section{ORCID}

Sang Hun Kim: https://orcid.org/0000-0002-1710-4661

Su Yeong Park: https://orcid.org/0000-0001-7108-4350

\section{REFERENCES}

1. Park JS, Baek CW, Kang H, Cha SM, Park JW, Jung YH, et al. Total intravenous anesthesia with propofol and remifentanil in a patient with MELAS syndrome -a case report-. Korean J Anesthesiol 2010; 58: 409-12.

2. Niezgoda J, Morgan PG. Anesthetic considerations in patients with mitochondrial defects. Paediatr Anaesth 2013; 23: 785-93.

3. Lee S, Kim BH, Lim K, Stalker D, Wisemandle W, Shin SG, et al. Pharmacokinetics and pharmacodynamics of intravenous dexmedetomidine in healthy Korean subjects. J Clin Pharm Ther
2012; 37: 698-703.

4. Fujita Y, Inoue K, Sakamoto T, Yoshizawa S, Tomita M, Maeda $\mathrm{Y}$, et al. A comparison between dosages and plasma concentrations of dexmedetomidine in clinically ill patients: a prospective, observational, cohort study in Japan. J Intensive Care 2013; 1: 15.

5. Sproule DM, Kaufmann P. Mitochondrial encephalopathy, lactic acidosis, and strokelike episodes: basic concepts, clinical phenotype, and therapeutic management of MELAS syndrome. Ann N Y Acad Sci 2008; 1142: 133-58.

6. Bains R, Moe MC, Vinje ML, Berg-Johnsen J. Sevoflurane and propofol depolarize mitochondria in rat and human cerebrocortical synaptosomes by different mechanisms. Acta Anaesthesiol Scand 2009; 53: 1354-60.

7. Withington DE, Decell MK, Al Ayed T. A case of propofol toxicity: further evidence for a causal mechanism. Paediatr Anaesth 2004; 14: 505-8.

8. Schläpfer M, Piegeler T, Dull RO, Schwartz DE, Mao M, Bonini MG, et al. Propofol increases morbidity and mortality in a rat model of sepsis. Crit Care 2015; 19: 45.

9. Suleman MI, Edala T, Abraham E, Siddiqu MS. Non-trigger anesthesia management in a patient with Leigh's syndrome presenting for dental rehabilitation. Anesth Pain Med 2015; 5: e28804.

10. Campagna JA, Miller KW, Forman SA. Mechanisms of actions of inhaled anesthetics. N Engl J Med 2003; 348: 2110-24.

11. Chen J, Shen N, Duan X, Guo Y. An investigation of the mechanism of dexmedetomidine in improving postoperative cognitive dysfunction from the perspectives of alleviating neuronal mitochondrial membrane oxidative stress and electrophysiological dysfunction. Exp Ther Med 2018; 15: 2037-43.

12. MacLaren R. Immunosedation: a consideration for sepsis. Crit Care 2009; 13: 191.

13. Gertler R, Brown HC, Mitchell DH, Silvius EN. Dexmedetomidine: a novel sedative-analgesic agent. Proc (Bayl Univ Med Cent) 2001; 14: 13-21.

14. Chattopadhyay U, Mallik S, Ghosh S, Bhattacharya S, Bisai S, Biswas H. Comparison between propofol and dexmedetomidine on depth of anesthesia: a prospective randomized trial. J Anaesthesiol Clin Pharmacol 2014; 30: 550-4. 